Article

\title{
Cretaciella sorianoae gen. et sp. nov. (Coleoptera, Leiodidae, Cholevinae, Oritocatopini), Anophthalmic Species from Albian Amber of the Escucha Formation (Alava, Spain)
}

\author{
Michel Perreau \\ IUT Paris Diderot, Université de Paris, 20 quarter rue du département, 75018 Paris, France; \\ michel.perreau@u-paris.fr
}

Received: 16 October 2019; Accepted: 5 December 2019; Published: 17 December 2019

\begin{abstract}
Cretaciella sorianoae gen. et sp. nov. (Coleoptera, Leiodidae, Cholevinae, Oritocatopini) from Albian amber of the Escucha Formation (Alava, Spain) is described and illustrated. This is the first species of Leiodidae from Alava amber and the first Cholevinae from Cretaceous amber. External and internal structures are investigated by propagation phase contrast X-ray microtomography. Based on both external and genital structures, Cretaciella is tentatively placed in the tribe Oritocatopini, the extant species of which occur in Sub-Saharan Africa. This specimen has no visible eyes or hind wings, which suggests an adaptation to subterranean or at least to soil litter environments. The biogeography of the tribe is succinctly discussed.
\end{abstract}

Keywords: Spanish amber; Mesozoic; anophthalmy; new genus; new species; connection of Cretaceous and Recent faunas

\section{Introduction}

The family Leiodidae presently comprises 4300 extant species or so, distributed worldwide, and organized into six subfamilies.

To date, Cretaceous amber fossils of Leiodidae have been recorded exclusively from amber of the Albian-Cenomanian age originated from the Hukawng valley, in northern Myanmar with currently four species: two species of Coloninae [1,2], one of Camiarinae (Agyrtodini) [3], and one of Catopocerinae [4], but many undescribed specimens are presently under investigation.

The Albian deposit of Alava is located on the northern slope of Sierra de Cantabria on the southern margin of the Basque-Cantabrian basin which developed between the European and Iberian plates during the Cretaceous period [5-7]. It is now a second source of Cretaceous amber Leiodidae. Many species of Staphylinoidea have been recorded from this deposit, especially Pselaphinae [8] and in this paper, the first species of Leiodidae, presumably belonging to Cholevinae Oritocatopini, is described.

Cholevinae contains approximately half of the species of Leiodidae and the small tribe Oritocatopini (three extant genera and 19 species) is the single tribe of Cholevinae inhabiting (and endemic to) Sub-Saharan Africa. The presence of a species of Oritocatopini in a Cretaceous Laurasian landmass implies dispersion to or from Sub-Saharan Africa.

The specimen has apparently no visible eyes and hind wings, which suggests adaptation to environments at and in soil, but its poor preservation conditions (especially at the level of the head and the pronotum) prevent a definitive conclusion to be made about the anophthalmy. 


\section{Materials and Methods}

External and internal structures are illustrated using both visible light observations and propagation phase contrast synchrotron microtomography (PPC-Sr $\mu$ CT) [9]. Microtomographic observations allow a complete virtual dissection of specimens in a non-destructive way [10]. They were performed at the European Synchrotron Radiation Facility (ESRF, Grenoble, France). Scans were performed on the beamline ID19 with a monochromatic X-ray beam at the energy of $20 \mathrm{Kev}$, using a multilayer monochromator. The CCD detector was a FreLoN HD2k (fast read-out low noise) with $2048 \times 2048$ pixels, coupled to a microscope system with a single crystal YAG(Ce) scintillator screen, $25 \mathrm{~mm}$ in thickness. The resolution (voxel size) of the scans was 0.678 micrometers. A continuous rotation was used to blur out details located outside the field of interest (far from the rotation center and generally undesired) in order to decrease their contribution to the noise of the final reconstructed slices [11].

Tomographic reconstructions were performed with the in-house software of ESRF and segmentations were performed with the software Vgstudiomax 2.1 (Volumegraphics, Heidelberg, Germany) run on a computer based on an AMD motherboard Magny-Cours (48 cores) and 512 GB of random access memory.

The microtomographic data linked to these specimens (original slices and processed data) and used for the present paper are publicly available on the ESRF online paleontological database [12].

Some structural details, which are not appropriately illustrated even by tomographic pictures, due to the bad preservation conditions of the specimen or the weak contrast generally observed with Cretaceous samples, are also illustrated in three dimensional anaglyphs. They can be visualized with red/cyan glasses. The corresponding standard and anaglyph pictures have the same letter with an additional number " 1 " (standard) or " 2 " (anaglyph). When only the standard picture is given, no number is added.

Visible light pictures were acquired on a Keyence (Osaka, Japan) VHX5000 microscope and a VH-Z250T lens.

\section{Taxonomy}

Cretaciella gen. nov.

Type species: Cretaciella sorianoae sp. nov.

Diagnosis: maxillary palpi with very long apical segment (more than 1.9 times as long as penultimate one); weak occipital carina; no visible eyes and hind wings; presence of mesoventral process; closed procoxal cavities; abdominal ventrites with transverse rows of strong setae; elytra with transverse alignments of punctation and visible longitudinal stria on posterior outer sides; protibiae without a row of external spines of equal length; all tarsi pentamerous; aedeagus with parallel basal lamella and triangular shape of median lobe, abdominal segment IX (genital segment) with sclerotized lateral epimera but membranous dorsal and ventral parts.

Cretaciella sorianoae sp. nov.

Holotype male: Spain, amber of the Albian deposit of the Escucha Formation of Alava, at the Peñacerrada I locality, housed in the Museum of Natural Sciences of Alava (MCNA) under the reference MCNA9423.

\section{Description}

Length: $1.70 \mathrm{~mm}$. Habitus figured in lateral view (usual optics in Figure 1a and tomographic reconstructions in Figure 1(b1,b2)) and dorsal view (Figure 1c). A video in rotation, based on tomographic reconstructions is given as Supplementary Materials.

Antenna with 11 segments, 2nd to 9th antennomeres asymmetric, thicker on outer side than inner side, antennomere 8 reduced in length (Figure 1d). Quadri-segmented maxillary palpi, narrow, and elongated, thin apical palpomere 1.9 times as long as the penultimate one (Figure 1e). Anterior part of the pronotum and posterior part of head strongly impressed by an undetermined process, 
making uncertain the appreciation of some characters (Figure 1c). Presence of occipital carina unclear and no visible eyes (Figure $1(\mathrm{f} 1, \mathrm{f} 2)$ ).

Transverse pronotum, approximately 1.8 times wider than long. Lateral sides strongly curved, posterior angles rounded, widest at posterior third. Curvature of lateral body outlines not continuous, interrupted between pronotum and elytra. Procoxal cavities closed posteriorly by processes of prohypomera (Figure 2(a1,a2)). Mesoventrite with mesocoxae separated by mesoventral process with long setae along ventral surface (mesoventral process (mvp) shown in Figure 2(b1,b2)). Long setae along margins of mesocoxae (Figure 2(b1,b2)).

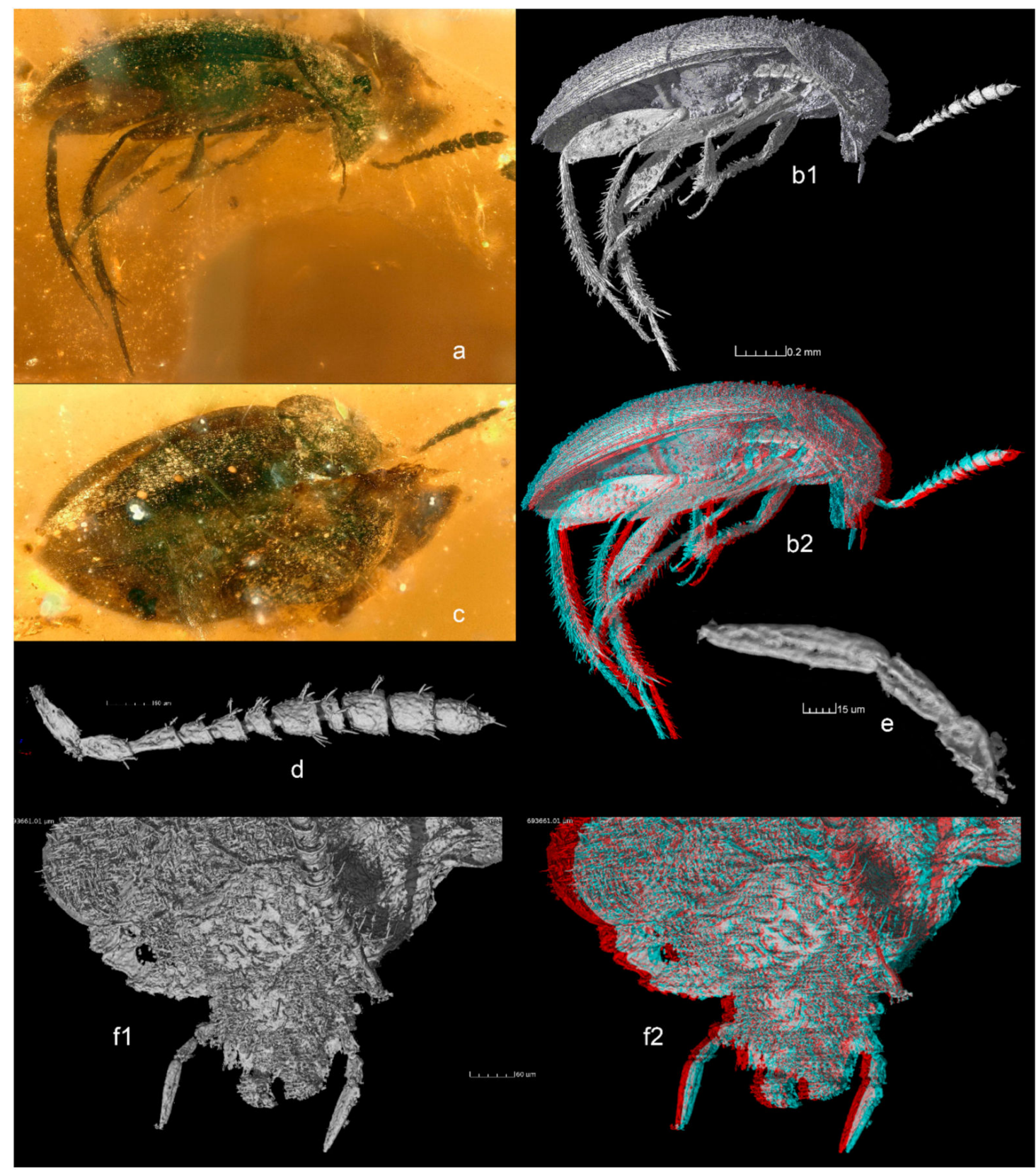

Figure 1. Cretaciella sorianoae gen. et sp. nov. (a) Habitus, lateral view (usual optics). (b1,b2) Same, lateral view (tomographic reconstruction). (c) Same, dorsal view (usual optics). (d) Left antenna. (e) Maxillary palpus. (f1,f2) Head and pronotum, frontal view. 


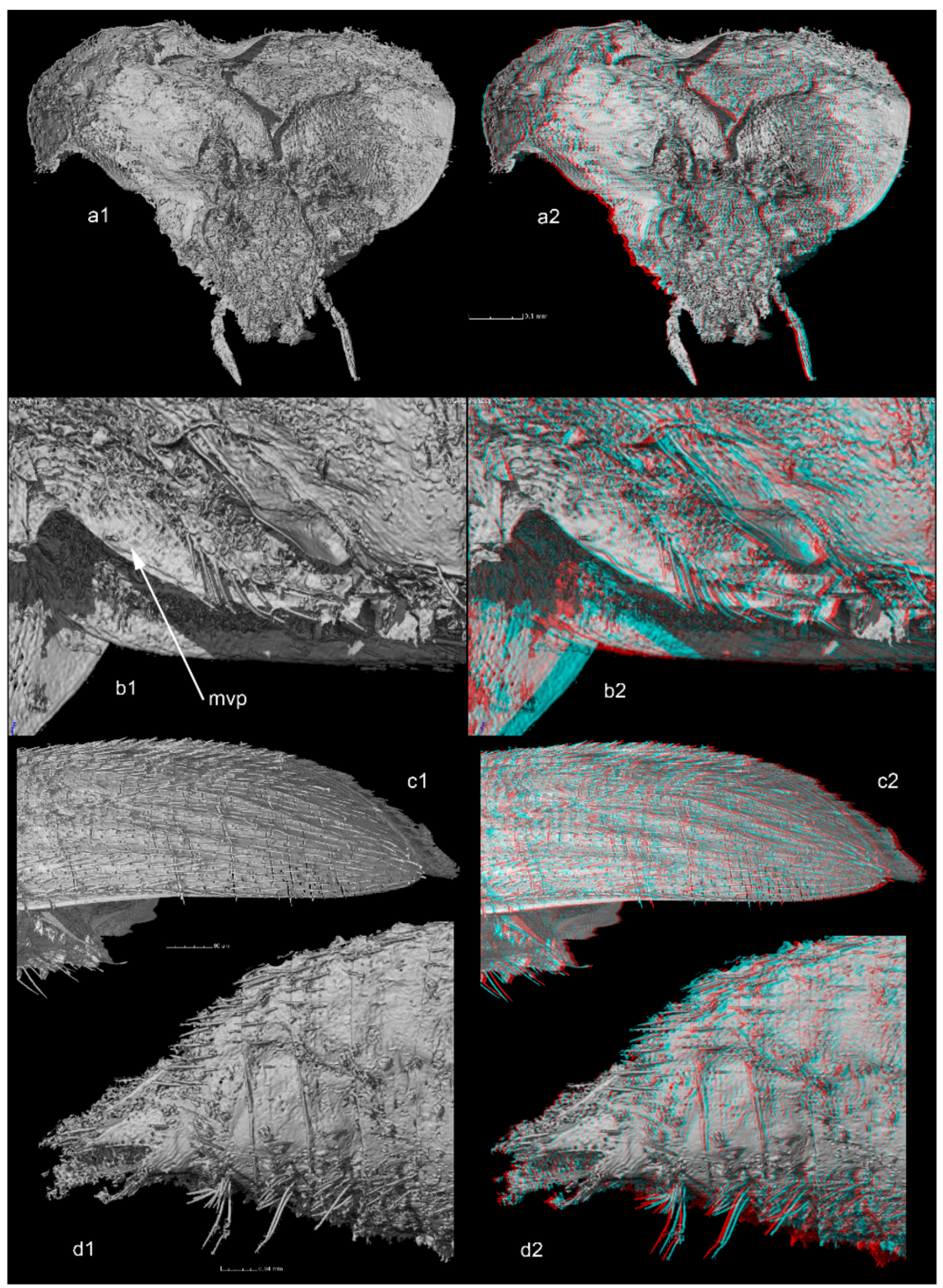

Figure 2. Cretaciella sorianoae gen. et sp. nov. (a1,a2) Ventral side of prothorax with prosternal structures (fore legs removed). (b1,b2) Mesoventral process with lateral strong setae (middle legs removed, mvp-mesoventral process). (c1,c2) Apex of elytra lateral view (striae and interstrial ridges). $(\mathbf{d} 1, \mathbf{d} 2)$ Abdomen in lateroventral view (elytra removed) with transverse row of strong setae on ventrites.

Elytra with tiny punctation associated with recumbent setae, aligned in transverse rows, but not in distinct transverse strigae. Parasutural longitudinal stria limited to middle third of elytral length. Six stria demarcating five distinct interstrial ridges on posterior outer sides of elytra (Figure 2(c1,c2)). Hind wings not visible (including in reconstructions after tomography), probably absent.

Abdomen with six visible ventrites. All visible ventrites with a transverse row of extremely long setae in the middle (Figure 2(d1,d2)).

Protibias regularly thickened from base to apex, with no row of regular spines of equal length on outer side but with a few sparse spines (Figure 3a). Mesotibias strongly arcuate (Figure 3b). Metatibias moderately arcuate (Figure 3c). Metafemur with oblique median ventral spine (sp on Figure 3c). Meso and metatibias with strong spines on outer side. Tarsal formula 5-5-5. Protarsi widely dilated (Figure 3a), approximately as wide as protibial apex. Empodium with two setae. 


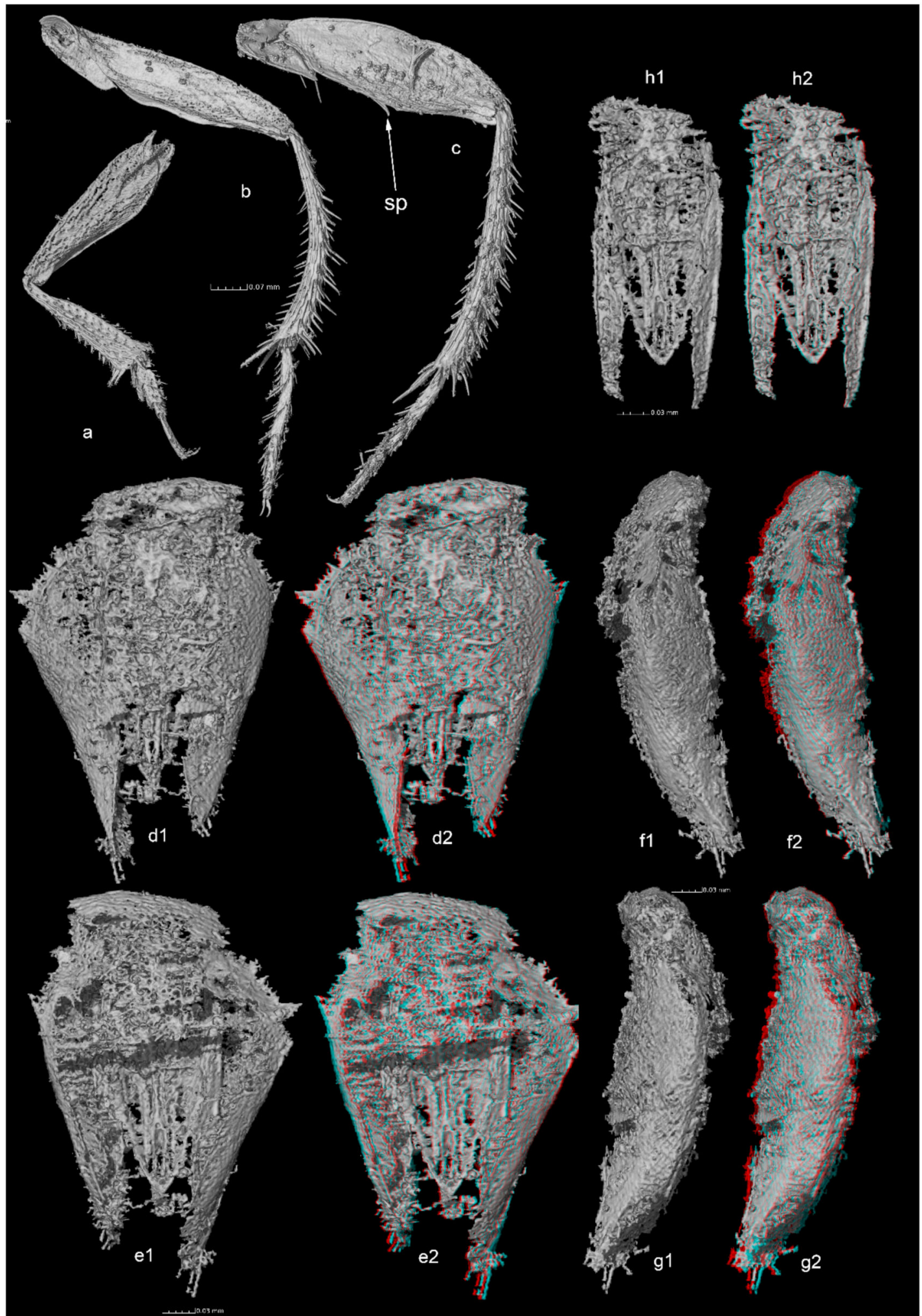

Figure 3. Cretaciella sorianoae gen. et sp. nov. (a) Right fore leg, dorsal view. (b) Right middle leg, dorsal view. (c) Right hind leg, dorsal view (sp-femoral spine). (d1,d2) Genital segment, ventral view. (e1,e2) Same, dorsal view. (f1,f2) Same, right lateral view. (g1,g2) Same, left lateral view. (h1,h2) Aedeagus, dorsal view.

Genital segment and aedeagus visible in tomographic reconstructions. Genital segment elongated and triangularly reduced from base to apex, membranous on dorsal and ventral parts, epipleurites 
sclerotized, with set of apical setae (Figure 3(d1-g2)). Aedeagus with triangular median lobe and flat parameres, slightly convergent at apex and extending beyond tip of median lobe. Basal lamella of tegmen wide and roughly parallel (Figure $3(\mathrm{~h} 1, \mathrm{~h} 2)$ ). No visible internal structure in endophallus.

Etymology: The species is dedicated to Carmen Soriano who worked extensively on the fauna of the Alava deposit and interested the author in this specimen.

\section{Discussion}

\subsection{Systematic Placement}

The combination of the following external and internal characters suggests placement of the new genus in Oritocatopini: maxillary palpi with a very long apical segment; presence of mesoventral process; procoxal cavities closed posteriorly; protibias without a row of external spines of equal length; all tarsi pentamerous; weak occipital carina; aedeagus with parallel basal lamella and triangular median lobe; genital segment with membranous dorsal and ventral parts.

Neither the mesothoracic epimera and episterna nor the internal structure of the endophallus, which could confirm the placement in Oritocatopini, were visible due to poor preservation of the sample.

The main differences from other genera of the tribe are the asymmetric antennal club, the elytral ridges on the elytra and the transverse rows of extremely long setae along the middle of the abdominal ventrites. The following key (modified from Jeannel [13]) can be used for the identification of the genera Oritocatopini.

\subsection{Identification Key of Genera Oritocatopini}

1. Abdominal ventrites with a transverse row of long setae in the middle. Elytra with five distinct interstrial ridges on their posterior lateral sides. Asymmetric antennal club. Probably anophthalmic

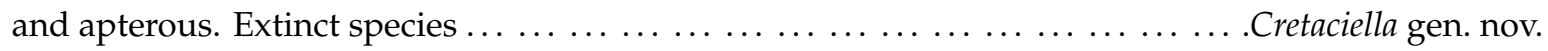

-Abdominal ventrites without a transverse row of long setae. Elytra without both stria (except the parasutural) and ridges. Symmetric antennal club. Species with eyes (sometimes with reduced eyes, but never lacking) and with or without hind wings. Extant species . . . . . . . . . . . . ...2.

2. Transverse strigae of elytra oblique. Species with developed eyes and hind wings. Thick antennal club. Convex body, short pronotum, and strongly transverse ... ......Afrocatops Jeannel, 1964.

- Transverse strigae of elytra perpendicular to the suture. Hind wings absent. Thin antennal club.

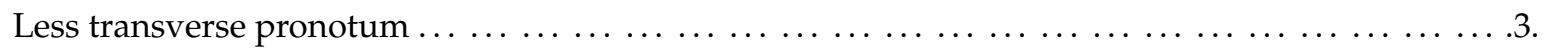

3. Smaller (less than $2.9 \mathrm{~mm}$ long), subovoid in shape. Transverse strigae of elytra more distinct

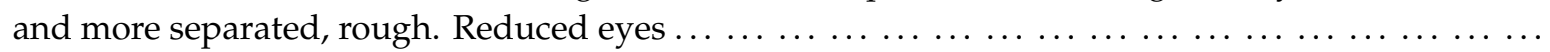

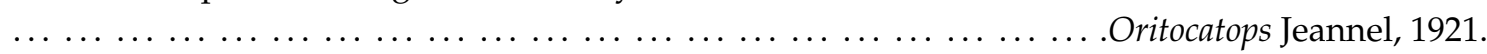

- Larger (more than $3.1 \mathrm{~mm}$ long), with a lenticular shape. Transverse strigae of elytra thin, more superficial and dense. Normally developed eyes .................Chappuisiotes Jeannel, 1936.

\subsection{Biogeography}

The current geographical distribution of Oritocatopini is illustrated in Figure 4 (including the present location of the fossil species). The extant species occur exclusively in Sub-Saharan Africa [13]. They are supposed to be of Gondwanian origin, having migrated from south to north creating interrupted relict distribution represented by two widely distant and disconnected areas: Austral Africa (Western Cape Province, Eastern Cape Province, Kwazulu-Natal), and the Rift Valley region (Republic of Congo, Rwanda, Burundi, Uganda, Kenya, North of Tanzania) [14,15]. According to this dispersal hypothesis, the discovery of Cretaciella in Spain is an example of Transtethyan migration from Gondwana (Africa) to Laurasia. Transitory land routes through discontinuous emergent platforms occurred during the late Cretaceous period [16], far earlier than the final connection of Africa and Laurasia during the Miocene period [17]. 
Cretaceous Oritocatopini could also have had a Circumthetyan range due to spreading just before the late Triassic breakup of Pangea. This would imply a radiation of Oritocatopini before the Jurassic period, which is not presently documented through known fossils.

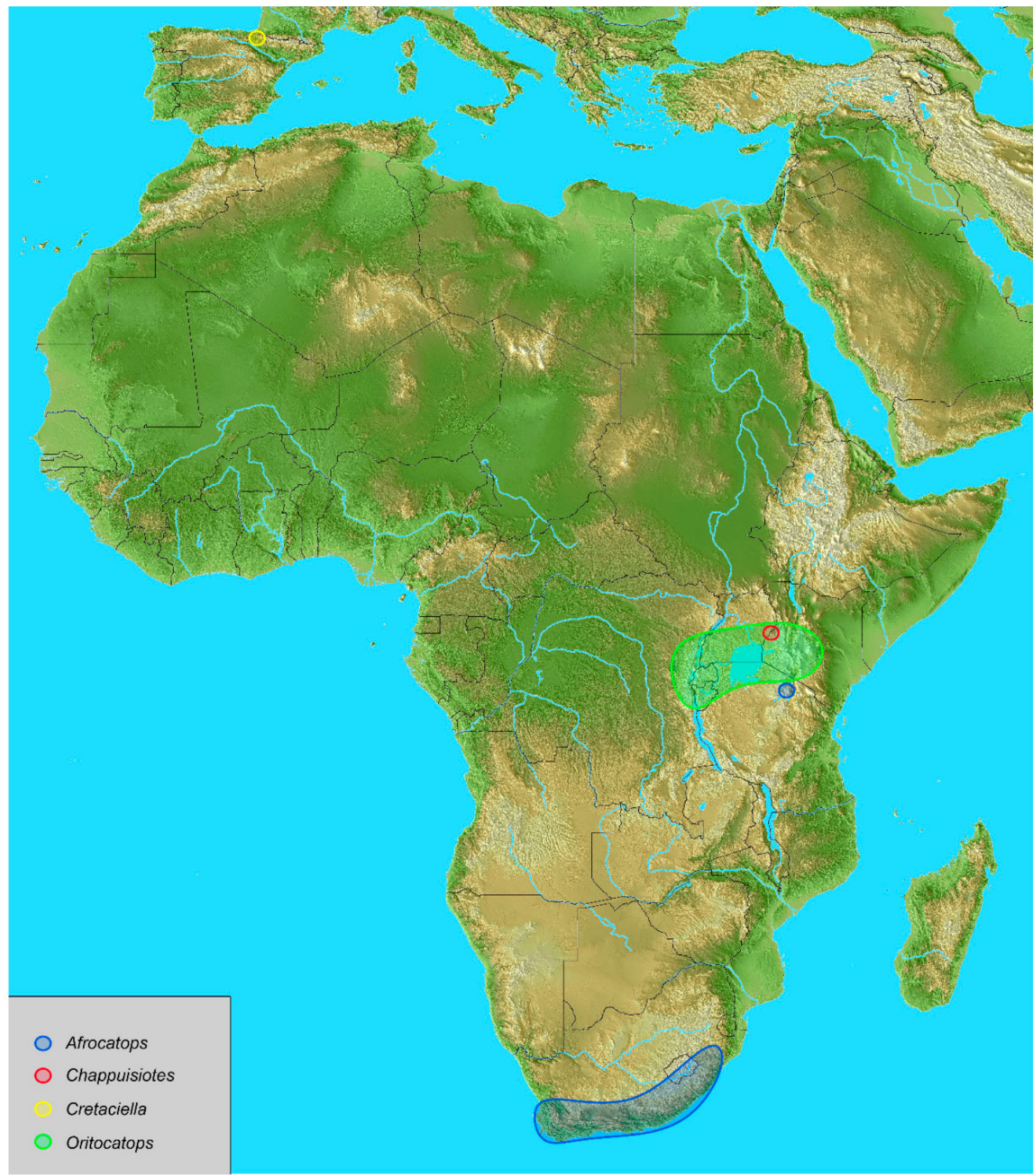

Figure 4. Present distribution area of the tribe Oritocatopini (including the present location of the fossil species).

\subsection{Ecology}

No extant species of Oritocatopini are anophthalmic, but species of the genus Oritocatops Jeannel, 1936, show a significant reduction of the eyes [13].

Considering the absence of eyes, the possibility of an artifact due to the poor preservation of the sample cannot be completely excluded. However, for the normally eyed species, the eyes are visible at first glance, without ambiguity. In Cretaciella, no ocular structures (pieces of eyes, facets) on either side of the head were revealed, either with usual optics or after tomographic reconstruction. It was considered highly unlikely that both eyes could have been completely destroyed when other epicranial 
structures such as palpi and antennae remained fairly preserved. (Usually, the insertions of antennae are very close to the eyes, when they are present.)

The probable absence of eyes suggests an adaptation to subterranean or at least soil habitats. Species living within the ground may also be trapped in amber as exudation of resin from trees can occur from the roots directly into the ground [18].

If the anophthalmy of Cretaciella sorianoae is confirmed by further specimens, it will support the hypothesis that ancient leiodids, like modern representatives, could have a subterranean or soil litter lifestyle. Most subterranean or soil litter extant species of Coleoptera belong to Leiodidae and Carabidae, as the two most likely anophthalmic Cretaceous fossils: Cretaciella sorianoae and Kryzhanovskiana olegi Kataev and Kirejtshuk, 2019 [19].

Supplementary Materials: The following are available online at http://www.mdpi.com/2076-3263/9/12/521/s1, Video: Cretaciella_sorianoae_Perreau_habitus_rotation_video_anaglyph.avi.

Funding: This research was funded by the ESRF under the experiments EC530 and LS2248.

Acknowledgments: We are indebted to Paul Tafforeau (ESRF) and Carmen Soriano for their participation to the reconstruction and segmentation of the tomographic scans. We also thank the three anonymous referees for their fruitful suggestions.

Conflicts of Interest: The authors declare no conflicts of interest.

\section{References}

1. Cai, C.; Huang, D. First fossil Coloninae from Upper Cretaceous Burmese amber (Coleoptera: Staphylinoidea: Leiodidae). Cretac. Res. 2017, 77, 69-74. [CrossRef]

2. Yamamoto, S.; Takahashi, Y. First discovery of fossil Coloninae in cretaceous burmese amber (Coleoptera, Staphylinoidea, Leiodidae). Paläontol. Z. 2018, 92, 195-201. [CrossRef]

3. Cai, C.; Huang, D. First definitive fossil agyrtodine beetles: An extant southern hemisphere group recorded from Upper Cretaceous Burmese amber (Coleoptera: Staphylinoidea: Leiodidae). Cretac. Res. 2017, 78, 161-165. [CrossRef]

4. Perreau, M. Archaeocerus uenoi n. gen. n. sp. (Coleoptera Leiodidae Catopocerinae) from Albian/Cenomanian age amber of Myanmar. Zootaxa 2019, 4638, 595-600. [CrossRef] [PubMed]

5. Alonso, J.; Arillo, A.; Barrón, E.; Corral, J.C.; Grimalt, J.; López, J.F.; López, R.; Martínez-Delclòs, X.; Ortuño, V.M.; Peñalver, E.; et al. A new fossil resin with biological inclusions in lower Cretaceous deposits from Álava (Northern Spain, Basque-Cantabrian Basin). J. Paleontol. 2000, 74, 158-178. [CrossRef]

6. Delclós, X.; Arillo, A.; Peñalver, E.; Barrónc, E.; Soriano, C.; López Del Valle, R.; Bernárdez, E.; Corral, C.; Ortuño, V.M. Fossiliferous amber deposits from the Cretaceous (Albian) of Spain. Comptes Rendus Palevol 2007, 6, 135-149. [CrossRef]

7. Rodrigo, A.; Peñalver, E.; Lopez del Valle, R.; Barrón, E.; Delclòs, X. The heritage interest of the Cretaceous amber outcrops in the Iberian Peninsula, and their management and protection. Geoheritage 2018, 10, 511-523. [CrossRef]

8. Peris, D.; Chatzimanolis, S.; Delclòs, X. Diversity of rove beetles (Coleoptera: Staphylinidae) in Early Cretaceous Spanish amber. Cretac. Res. 2014, 48, 85-95. [CrossRef]

9. Tafforeau, P.; Boistel, R.; Boller, E.; Bravin, A.; Brunet, M.; Chaimanee, Y.; Cloetens, P.; Feist, M.; Hoszowska, J.; Jaeger, J.J.; et al. Applications of X-ray synchrotron microtomography for non-destructive 3D studies of paleontological specimens. Appl. Phys. A Mater. Sci. Process. 2006, 83, 195-202. [CrossRef]

10. Perreau, M.; Tafforeau, P. Virtual dissection using phase-contrast X-ray synchrotron microtomography: Reducing the gap between fossils and extant species. Syst. Entomol. 2011, 36, 573-580. [CrossRef]

11. Lak, M.; Néraudeau, D.; Nel, A.; Cloetens, P.; Perrichot, V.; Tafforeau, P. Phase contrast X-ray synchrotron imaging: Opening access to fossil inclusions in opaque amber. Microsc. Microanal. 2008, 14, 251-259. [CrossRef] [PubMed]

12. ESRF Heritage Database for Palaeontology, Evolutionary Biology and Archaeology. Available online: http://paleo.esrf.eu (accessed on 12 December 2019).

13. Jeannel, R. Les Catopides de l'Afrique australe avec une révision des Oritocatopini africains. in: The humicolous fauna of south Africa, Pselaphidae and Catopidae (Coleoptera). Transvaal Mus. Mem. 1964, 15, 220-255. 
14. Jeannel, R. La Gondwanie et le peuplement de l'Afrique. Ann. Mus. R. Af. Cent. Zool. 1961, 102, 42-141.

15. Giachino, P.M.; Vailati, D. Revisione degli Anemadinae Hatch, 1928 (Coleoptera Cholevidae). Monogr. Nat. Brescia 1993, 18, 314.

16. Gheerbrant, E.; Rage, J.-C. Paleobiogeography of Africa: How distinct from Gondwana and Laurasia? Palaeogeogr. Palaeoclimat. Palaeoecol. 2006, 241, 224-246. [CrossRef]

17. Le Gall, P.; Silvain, J.-F.; Nel, A.; Lachaise, D. Les insectes actuels témoins des passés de l'Afrique: Essai sur l'origine et la singularité de l'entomofaune de la région afrotropicale. Ann. Soc. Entomol. Fr. 2010, 46, 297-343. [CrossRef]

18. Martínez-Delclós, X.; Briggs, D.E.G.; Peñalver, E. Taphonomy of insects in carbonates and amber. Palaeogeogr. Palaeoclimat. Palaeoecol. 2004, 203, 19-64. [CrossRef]

19. Kataev, B.M.; Kirejtshuk, A.G.; Manukyan, A.R.; Anokhin, B.A. Kryzhanovskiana olegi gen. et sp. nov., a remarkable eyeless representative of the tribe Metriini (Coleoptera: Carabidae: Paussinae) from Upper Cretaceous amber of northern Myanmar. Cretac. Res. 2019, 103, 104168. [CrossRef]

(C) 2019 by the author. Licensee MDPI, Basel, Switzerland. This article is an open access article distributed under the terms and conditions of the Creative Commons Attribution (CC BY) license (http://creativecommons.org/licenses/by/4.0/). 